\title{
Direito Constitucional entre passado e futuro: Análise do papel e da organização da jurisdição constitucional do STF na realidade jurídico constitucional brasileira
}

Constitucional Right between the past and future: Analysis of the role and organization of the constitutional jurisdiction of the STF in the Brazilian constitutional legal reality

\section{Vivian Cristina Lima López Valle ${ }^{1}$}

Resumo: O artigo busca analisar o Direito Constitucional e seus momentos históricos, contextualizando a formação e transformação do discurso constitucional e a estrutura da jurisdição constitucional contemporânea. Busca interpretar as capacidades institucionais e processo decisório da jurisdição constitucional,

1 Doutora e mestre em Direito do Estado pela Universidade Federal do Paraná - UFPR. Pós-doutoranda pela Universitat Rovira i Virgili na Espanha. Possui especialização em Direito Administrativo pelo IBEJ e em Contratação Pública pelo Centro de Estudos de Direito Público e Regulação da Faculdade de Direito da Universidade de Coimbra, Portugal. Atua nos cursos de especialização da Pós-Graduação PUCPR, do Instituto de Direito Romeu Bacellar, da Fundação Escola Superior do Ministério Público de Mato Grosso, da Escola da Policia Civil do Estado do Paraná e da Universidade Positivo. É integrante do Instituto Paranaense de Direito Administrativo, do Núcleo de Investigações Constitucionais NINC/ UFPR, do Núcleo de Pesquisas em Direito Administrativo, Urbanístico e Ambiental da UFPR - Pró-polis. 
apontando uma crise de representação e necessidade de construção de um novo espaço-temporal para o Direito Constitucional, mais efetivo, inclusivo, dialético, reflexivo, dialógico, de disputabilidade e aberto. Aponta-se que o constitucionalismo necessariamente terá que enfrentar a questão dos diálogos constitucionais, de interpretação substantiva, e defende-se um novo arranjo institucional capaz de enfrentar adequadamente a ausência de motivação suficiente da tomada de decisão, de disputabilidade intersubjetiva, de deliberação e debate, de argumentação forte. Em vista disso, entende-se que o STF precisa enfrentar a ausência de capacidade institucional de colaboração e de uma pauta pré definida e de discussão democrática sobre o que integrará a pauta. Finaliza-se apontando a ausência de uma identidade de Corte Constitucional no STF e a necessidade de reformulação de sua estrutura, para atender adequadamente as demandas por direitos fundamentais contemporâneas.

Palavras-chave: Jurisdição Constitucional. Novos arranjos institucionais. Direito Constitucional mais efetivo, inclusivo, dialético, reflexivo, dialógico, de disputabilidade e aberto.

Abstract: The article seeks to analyze Constitutional Law and its historical moments, contextualizing the formation and transformation of the constitutional discourse and the structure of the contemporary constitutional jurisdiction. It seeks to interpret the institutional capacities and decision-making process of the constitutional jurisdiction, pointing to a crisis of representation and the need to construct a new spacetime for Constitutional Law, more effective, inclusive, dialectical, reflexive, dialogical, disputable and open. It was pointed out that constitutionalism will necessarily have to face the issue of constitutional dialogues, 
of substantive interpretation. A new institutional arrangement capable of adequately addressing the lack of sufficient motivation for decision-making, intersubjective contentability, deliberation and debate, and strong argumentation. It was argued that the STF must face the absence of institutional capacity for collaboration and a pre-defined agenda and democratic discussion on what will integrate the agenda. It ends by pointing to the absence of a constitutional court identity in the Supreme Court and the need to reformulate its structure tomeet the demands adequately for contemporary fundamental rights.

Keywords: Constitutional Jurisdiction. New institutional arrangements. Constitutional law more effective, inclusive, dialectical, reflexive, dialogical, of disputability and open.

Sumário: 1. Direito Constitucional e seus momentos históricos. 2. A definição da reserva de justiça em face dos direitos fundamentais. 3. Capacidades institucionais e processo decisório da jurisdição constitucional - crise de representação e necessidade de construção de um novo espaço-temporal para o Direito Constitucional. 4. Por um Direito Constitucional efetivo, inclusivo, dialético, reflexivo, dialógico, de disputabilidade e aberto. 5. Referências.

\section{Introdução: Direito Constitucional e seus Momentos Históricos}

O desenvolvimento histórico do Direito Constitucional a partir da Constituição de 1988 passou por diferentes momentos, numa busca por identidade e mais posteriormente, 
por efetividade e representatividade. São diferentes tempos, com substancialmente diferentes possibilidades jurídicas de interpretação do discurso constitucional.

Da discussão da identidade do discurso constitucional à discussão da maquinaria constitucional ${ }^{2}$ representativa e efetiva, o fato é que faz-se necessário discutir qual o direito constitucional que se pretende desenvolver, e qual o papel da jurisdição constitucional na defesa dos interesses fundamentais da sociedade brasileira.

$\mathrm{O}$ argumento aqui exposto pode ser resumido nos seguintes termos: Qual o lugar para a eficácia e representatividade do direito constitucional na sociedade contemporânea? Qual a organização constitucional capaz de conferir ao discurso constitucional efetividade e representatividade?

Um dos primeiros momentos do discurso constitucional passou pela tentativa de imposição de um discurso de transformação do discurso constitucional normativo para um discurso constitucional instrumental, culminando num mecanismo perverso de seletividade das disposições constitucionais. $^{3}$

A grande preocupação era a identidade do discurso constitucional, e a eficácia da regulação tradicional pela via do Direito, a validade de outras formas de regulação social,

2 Cleve, Clemerson Merlin. Governo Democrático e Jurisdição Constitucional. Porto Alegre, Editora Fórum, 2016.

3 Nesse sentido cabe destacar que a Constituição de 1988 foi significativamente discutida sob o enfoque do neoliberalismo e sua pretensão de ressaltar a importância da análise econômica das relações nas sociedades humanas contemporâneas. Na área jurídica as políticas neoliberais implicaram na estipulação de um Estado mínimo, numa tentativa de dilapidação do modelo social de Estado e isso afetou o discurso constitucional. $\mathrm{O}$ neoliberalismo legitimou seu discurso endossando teses pós - modernas como o fim da história, a irreversível vitória do mercado e de suas instituições, a reforma do Estado, a impossibilidade de regulação pelo direito dos novos fenômenos sociais, a ausência de normatividade do texto constitucional. 
e concepção da desregulamentação como apelo indireto a um outro direito, apto a dominar a complexificação das relações sociais assim como a mundialização dessas relações que trouxeram perturbações nas respostas clássicas a esses problemas. ${ }^{4}$

Efetivamente evidenciava-se no mundo contemporâneo uma erosão da normatividade constitucional. O Direito Constitucional perdia no ambiente do neoliberalismo substância e conteúdo, fragilizava-se com a insegurança jurídica imposta pelos detentores do poder político (e econômico, por óbvio) na busca pela instrumentalização da Constituição. Ocorria uma desubstancialização da Constituição.

A discussão do passado, nesse sentido, estava ligada à identidade e essência, e por isso o desenvolvimento de um discurso de fortalecimento da referência ao território constitucional, uma reação no sentido preservar a substância e a essência do texto constitucional, num movimento de resubstancialização do Direito, com aproximação do Direito com o saber jurídico e o saber principiológico. Toda a teoria constitucional se voltou à afirmação do discurso constitucional substancializado nos direitos fundamentais. Esse momento histórico é o da afirmação do Direito Constitucional.

O tempo demonstrou que as promessas neoliberais não se realizaram e o Direito Constitucional fortaleceu o discurso da substancialização de seu conteúdo, da filtragem constitucional do ordenamento jurídico e da defesa dos direitos fundamentais.

$4 \quad$ E sob esse pano de fundo evocava-se um recuo do Estado visível através do desenvolvimento da normalização e da certificação, com a associação do setor privado com os poderes públicos na produção do direito. O direito estatal, e por consequência o próprio direito constitucional, corria o risco de ser concretamente suplantado por outros tipos de regulação global em decorrência do aparecimento de ordens espontâneas que escapavam à regulação estatal, bem como pela ameaça que pesava sobre o equilíbrio internacional. 
Clémerson Merlin Clève afirma um segundo momento de fundamentação, onde se buscou desenvolver o problema da jurisdição constitucional, o aprofundamento do estudo dos direitos fundamentais. Esse estudo exigia a reconstrução da doutrina brasileira. Não mais de afirmação da normatividade, mas que pudessem resolver os problemas da teoria jurídica. A construção de uma nova dogmática, num campo do pós positivismo. ${ }^{5}$ Há uma comunhão de simpatia pela Constituição mas a questão é saber como operá-la.

$E$ as dificuldades se iniciam quando se constata que a Constituição não é transparente. Qual Constituição deve ser aplicada? Segundo qual visão? Para questões difíceis as respostas poderão ser muito variadas a depender do enfoque que se dá à Constituição, com soluções antagônicas entre si em diferentes momentos. Esse também é um argumento a ser discutido. ${ }^{6}$

O problema do presente é de outra ordem e está relacionado à percepção de que o papel da jurisdição constitucional é importante mas não é suficiente para a realização das promessas de Constituição de uma sociedade livre com pessoas

5 Clève, Clemerson Merlin. Governo Democrático e Jurisdição Constitucional. Porto Alegre, Editora Fórum, 2016. Segundo o autor, há um abandono das doutrinas constitucionais positivistas. Há até um neoconstitucionalismo em sentido estrito, que acredita muito na força dos juízes e o desenvolvimento de uma doutrina constitucional extremamente sofisticada que está de alguma maneira dividida, pois há escolas de Direito Constitucional no Brasil dialogando com o pensamento critico dos anos 70 até escolas habermasianas, as escolas da ponderação de Alexy e as escolas hermenêuticas.

6 A Constituição é muito mais de regras do que de princípios. Essa abertura permite alcançar resultados distintos e igualmente lícitos. E portanto a Constituição não é transparente, especialmente em se tratando dos casos difíceis. Há uma disputa hermenêutica em relação à compreensão da Constituição. São teorias mais ou menos céticas apostando no controle decisional, acreditando na ideia de escolha constitucional ou apostando em ideias reguladoras ou na própria ideia da resposta correta. 
emancipadas e com justiça. Esse é o terceiro momento do Direito Constitucional.

O novo desafio do discurso constitucional é construir teorias que apontem para a solução deste problema: a construção de uma sociedade onde todos são tratados com igual consideração e respeito, onde não há níveis insuportáveis de desigualdade social, onde há realização material da justiça e dos direitos fundamentais. A emancipação do discurso constitucional do primeiro momento histórico precisa ser materializada e a discussão está em como se realizar essa tarefa e a partir de que referência.

No desenvolvimento da Constituição se percebe a definição da reserva de justiça e dos direitos fundamentais, organização do desenho institucional, com os poderes da República e a Federação (que Clémerson Merlin Clève denomina de maquinaria constitucional) e a democracia. Mas se identifica atualmente crises de representação. E esse deve ser o foco do estudo do discurso constitucional atual, especialmente focado na jurisdição constitucional.

No Brasil, há uma tendência de concentração do controle de constitucionalidade. Essa tendência já se vislumbra desde o início da discussão sobre a Constituição de 1988, inicialmente materializada com a Emenda Constitucional n. 03, mas desenvolvida com o manejo de instrumentos como a Arguição de Descumprimento de Preceito Fundamental e após a Emenda Constitucional n. 45, com as exigências de Repercussão Geral em sede de Recurso Extraordinário, de efeitos vinculantes em ADI e ADC e de ausência de uma cultura de precedentes e da súmula vinculante.

Nesse sentido Comella contrapõe dois modelos de controle de constitucionalidade: o modelo descentralizado (de matriz estadunidense inaugurado pelo caso Marbury $x$ Madison) e o modelo centralizado (teorizado por Hans Kel- 
sen no início do século XX) e defende o modelo centralizado. ${ }^{7}$ O debate sobre a jurisdição constitucional é importante no Brasil por conta da sobrecarga de direitos. Quando se sobrecarrega o sistema de direitos com direitos tão abstratos que são difíceis de serem cumpridos se desmoraliza o sistema. E nesse sentido cabe a pergunta: o melhor sistema é o que tem uma sobrecarga de direitos substantivos ou que protege os direitos substantivos essenciais e procedimentaliza os demais? Esse é um debate importante no Brasil. É a questão do custo dos direitos, que é tratada por diferentes autores, entre eles Cass Sunstein. ${ }^{8}$

7 O modelo centralizado (defendido pelo autor) tem como traço fundamental uma estrutura dualista (há uma corte constitucional e juízes ordinários). Segundo ele, a legitimidade das decisões de cortes desse tipo, historicamente, pode ser relacionada à divisão de poderes ou ao princípio da segurança jurídica. Para ele o modelo centralizado protegeria melhor os direitos fundamentais e os tribunais constitucionais poderiam lidar melhor com a norma constitucional, haja vista a necessária utilização de princípios de moralidade política. Ademais, esses mesmos tribunais contribuem aos debates na sociedade devido à sua alta visibilidade; por outro lado, sua propensão ao ativismo é necessária no embate político que, às vezes, é inevitável. COMELLA, Víctor Ferreres. Una Defensa del Modelo Europeo de Controle de Constitucionalidad. Madrid: Marcial Pons, 2011, pp. 13-167. Nesse ponto se percebe que estaría havendo um processo de abstrativização de um controle difuso no Brasil, numa espécie de convergência do civil law e do commom law. E exemplos são a sumula vinculante e a repercussão geral. Controle difuso com características abstratas. Na sumula vinculante não se vincula o caso, mas a lei, é diferente do precedente, onde se estuda o caso. A questão da convergência diz respeito ao fato de que a jurisdição constitucional no civil law não tem pauta para decidir como teria na sua atuação normal e isso a aproxima da commom law.

8 SUNSTEIN, Cass. A Constituição Parcial. Belo Horizonte: Del Rey Editora, 2008, p. 13 Arnaldo Sampaio de Moraes Godoy analisando a teoria de custos do Direito de Sunstein nesse sentido afirma: "A Constituição é muito mais de regras do que de princípios. Essa abertura permite alcançar resultados distintos e igualmente lícitos. E portanto a Constituição não é transparente, especialmente em se tratando dos casos difíceis. Há uma disputa hermenêutica em relação à compreensão da Constituição. São teorias mais ou menos céticas apostando no controle decisional, acreditando na ideia de escolha constitucional ou apostando em ideias reguladoras ou na própria ideia da resposta correta. (...). Argumentam 


\section{As teorias constitucionais atualmente buscam discutir} a representação da Corte Constitucional, as possibilidades de consenso, o grau de pureza da Corte a legitimar a sua atuação. No Brasil a discussão tem que partir de outra premissa, pois a Constituição aponta a legitimidade da jurisdição constitucional do STF. A questão não é de legitimidade, e sim de representação e jogo estratégico. ${ }^{9}$

também que os direitos têm custos sociais além dos custos orçamentários. Exemplificam a premissa com as medidas que se tomam para proteger direitos de acusados, em suposto desfavor do bem estar do cidadão que não teria contas para acertar com o Estado policial. Premissa problemática, à luz de nossas concepções de Justiça. (...).Holmes e Sunstein reconhecem problema metodológico que se deve enfrentar. Referem-se à dificuldade que se tem no cálculo dos custos dos direitos que o Governo se obriga a garantir. Não se pode saber, por exemplo, se despesas de treinamento de policiais se revertem, especificamente, para a humanização da atividade policial ou para a segurança geral da população. (...). Reconhecem, porém, que, embora seja um truísmo a concepção de que direitos tenham custos, pode-se invocar malicioso paradoxo: o cálculo dos custos dos direitos pode ameaçar a realização dos direitos cujos custos são calculados. Resumidamente, o reconhecimento dos custos dos direitos poderia explicitar que em troca de direitos deveríamos necessariamente pagar alguma coisa. Nós nos recusamos, no entanto, a precificar tudo que nos cerca. O direito ao júri demanda custos. De igual modo, e com mais intensidade, compensações que são pagas por desapropriação. Holmes e Sunstein argumentam que quando alguém chama a polícia está se impondo que a comunidade contribua para o pagamento de demanda individual. A judicialização de boa parte das discussões públicas faz com juízes decidam exatamente onde alocar o dinheiro dos contribuintes. Por isso, quando magistrados insistem numa conciliação, reconhecem que buscam economizar para o Estado. É essa a lógica que rege o modelo conciliatório norte-americano. Análise realizada pelo Professor Arnaldo Sampaio de Moraes Godoy, Professor da USP e da PUC/SP, publicada no consultor jurídico, link: http://www.conjur.com.br/2013-abr-07/embargosculturais-holmes-sunstein-demonstram-custo-financeiro-direitos\#author.

9 O fato de uma ação ser inconstitucional não significa que o Judiciário tenha competência para julgá-la. Esse era o entendimento na Europa e Marshall nos Estados Unidos naturaliza esse debate e afirma a competência em Marbury x Marshall. Essa é a discussão até hoje nos Estados Unidos. Se efetivamente a Suprema Corte tem legitimidade para efetivar o controle de constitucionalidade. Sunstein, Cass. A Constituição Parcial. Belo Horizonte: Del Rey Editora, 2008, p. 19. Esse debate que acontece nos USA está sendo trazido indevidamente para o Brasil, sem as devidas mediações, pois a Constituição aponta a legitimidade do STF. O que se pode fazer é 
Sunstein nesse sentido afirma que em muitas situações a Corte Constitucional tem a sensibilidade do momento político. Essa dimensão política da Corte Constitucional para o bem e para o mal precisa ser considerada. Esse raciocínio é preocupante especialmente pela função constitucional contra majoritária que a Corte deve desempenhar. $\mathrm{O}$ autor defende que o controle mais legítimo seria o abstrato porque as partes imbricadas falam. Outros defendem que o único controle legítimo é o abstrato. ${ }^{10}$

Uma estratégia é estabelecer um discurso normativo, prescritivo. Outra estratégia, de pensar em termos institucionais. São várias as estratégias. Clève afirma que são três os momentos do constitucionalismo após a Constituição de 1988 e que se precisa de três eixos de discussão simultâneos para resolver as questões constitucionais atuais.

O primeiro eixo é o Eixo da arena pública, uma Corte Constitucional exige uma arena pública, para que as ideias e interesses possam chegar à Corte.

O segundo eixo é o Eixo da metódica constitucional, não há lugar para o juiz Hércules mas é preciso que ele consiga fugir da sua subjetividade e para isso uma boa metódica é necessária. Mas sendo necessária não é suficiente. Se precisa restringir a área da subjetividade num ambiente livre de debate e precisa da metódica para expulsar os argumentos que não são cabíveis. Mas vai haver momento em que a metódica não consegue dar resposta, num campo entre política

discutir até onde o STF pode ir no controle de constitucionalidade. No Brasil, pelo sistema misto entre controle difuso incidental e concentrado principal há a possibilidade de jogo estratégico. Se a questão está madura pode se propor uma ADPF, se o debate ainda é insuficiente, se utilizaria do controle difuso incidental. Há um juízo estratégico que define se é o caso de buscar direto a tutela do STF ou de construir uma historia de debate no controle concreto até que haja uma maturidade da questão constitucional.

10 SUNSTEIN, Cass. A Constituição Parcial, Op. Cit., p. 27. 
e moralidade e esse é o papel mais importante de uma Corte Constitucional. O primeiro papel é unificar a jurisprudência e o outro é tomar decisões que a esfera política não está disposta a tomar ou que a arena política não decidiu.

O terceiro eixo é o Eixo da Teoria Constitucional e da reorganização institucional - onde a metódica não resolve a ideia de que pode haver mais de uma resposta correta e isso pode ser compatível com uma sociedade aberta. Nesse momento a Corte precisará decidir sobre decidir ou não decidir e o que decidir. A Suprema Corte Americana pode não decidir. Outras Cortes resolvem por outros caminhos.

No brasil se foge à questão por subterfúgios processuais ou procedimentais e nesse particular entra em questão o problema institucional, intrainstitucional, relacionado ao arranjo institucional entre o Poder Executivo, o Poder Legislativo e o Poder Judiciário.

Nessa relação interinstitucional há diálogo conflitivo e cooperativo e haverão ações, reações, decisão e não decisão e reações institucionais. Para isso, é necessário uma boa teoria constitucional. ${ }^{11}$

A esse respeito, Daniel Sarmento afirma que o STF não é o centro do constitucionalismo. Há um policentrismo no constitucionalismo, que não é só do STF mas da sociedade, do Poder Executivo como agente constitucional e do Legislativo. ${ }^{12}$ Para Clève, não seria correto dizer que não é o centro, mas é o centro mais frágil porque há outros centros. Esse é o momento atual do Direito Constitucional brasileiro.

11 Cleve, Clemerson Merlin. Governo Democrático e Jurisdição Constitucional. Porto Alegre, Editora Fórum, 2016.

12 SARMENTO, Daniel. "O STF não é o Centro do Constitucionalismo", Entrevista ao Site "Os Constitucionalistas", disponível em http://www. osconstitucionalistas.com.br/o-stf-nao-e-o-centro-do-constitucionalismo. 
O fato concreto é que a questão do custo dos direitos precisa ser avaliada e enfrentada, especialmente considerando que muitas vezes os direitos fundamentais dependem mais do Poder Executivo a materializar políticas públicas e da sociedade de exigi-los do que da própria jurisdição constitucional, que não é suficiente para garantir a materialização da Constituição e de suas promessas. Um constitucionalismo constitucionalmente adequado para uma sociedade periférica no século XXI.

As conclusões dessa análise necessariamente passarão pela constatação de que nem uma boa teoria processual nem uma boa metódica podem resolver o problema. Friedrich Mueller, nesse sentido reconhece a complexidade da questão política e propõe a construção de uma metódica. A dificuldade é que a construção da metódica significa a construção de um idioma que deve ser partilhado por todos e é muito difícil se conseguir essa ampla adesão. Os juízes adotam metódicas distintas e a Corte não pode decidir qual metódica será adotada ${ }^{13}$.

Comella afirma que haveria maior proteção aos direitos fundamentais se protegidos pela Corte. Existe uma certa "privatização da Constituição para o Direito". A Constituição não é só Direito, é um corpo político. Não se pode ignorar a contribuição de parlamentares e políticos que tem uma forte dimensão dos direitos, mas não o conhecimento técnico jurídico especifico. A Constituição não é um domínio para especialistas. É da cidadania, do povo, tem uma expressão política que não pode ser negada e esquecida.

13 MUELLER, Friedrich. Metódica Jurídica e Sistema Politico. Joinville: Bildung Editora, 2014. Essa constatação também se verifica em Alexy, o qual reconhece a insuficiência da metódica para atender à todos os casos difíceis do Direito Constitucional. (ALEXY, Robert. Epílogo a la teoria de los derechos fundamentales. Madrid: Fundación beneficentia et peritia iuris, 2004.) 
E Clève defende que há o momento da arena pública, o da metódica e o da Corte em articulação com os demais Poderes e com a sociedade. ${ }^{14}$ Esse é o atual momento do Direito Constitucional. Deve haver um reconhecimento que o Direito Constitucional também é discussão política e que há uma articulação da Constituição entre Direito, política e moralidade, estabelecendo uma filosofia moral.

Defende, ainda, que a adoção de uma tese normativa, prescritiva, é possível mas isso não vai significar que os demais ministros vão adotá-la, nem todos vão aderir. Haverá teses distintas e se necessita de mecanismos institucionais políticos, de poder e contra poder, e precisa-se compreender as virtuosidades do sistema, reconhecer as possibilidades de dialogo conflitivo além do diálogo cooperativo. Democracia também é diálogo conflituoso. Pode-se ter consenso em respeito a algumas coisas mas o modo de execução pode ser diferente. O diálogo é a possibilidade de ter uma resposta contrária, senão não é diálogo. E nesse contexto o debate de uma nova teoria constitucional se impõe.

Se é fato que não se pode esquecer a dimensão política do Direito Constitucional, também é fato que a Constituição não é transparente. Quando se está tratando de questões difíceis ou de princípios, a Constituição não é transparente e nem suficiente. Há a constituição invisível, aquilo que está fora da Constituição, e nesse terreno há debates absolutamente legítimos. Nesse momento as teorias da argumentação não são suficientes, muito menos a discricionariedade na decisão. É necessário substância, encontrada nas filosofias morais e políticas. Se trata ao mesmo tempo de mecanismos de restrição da discricionariedade do juiz.

14 CLEVE, Clemerson Merlin, op. Cit. 


\section{A Definição da Reserva de Justiça em face dos Direitos Fundamentais}

A definição de reserva de justiça em face dos direitos fundamentais é premissa de construção de uma teoria constitucional comprometida com a emancipação social e com uma sociedade sem níveis insuportáveis de desigualdade.

E nesse ponto imprescindível recorrer à teoria dos Direitos Fundamentais de Robert Alexy. Para o autor, direitos fundamentais têm caráter de princípios e os princípios são mandados de otimização, porém essa teoria encontra objeções. A maioria delas questiona se a tese dos mandados de otimização conduzem a um modelo adequado de direitos fundamentais e entre os principais questionadores está Habermas $^{15}$ e Böckenförde. ${ }^{16}$

15 Para Habermas, esse modelo enfraqueceria os direitos fundamentais: (...) os princípios apresentam um valor que deve ser realizado de forma ótima e se o grau de cumprimento deste mandado de otimização não pode ser obtido da norma por si mesma, a aplicação de tais princípios, no marco do faticamente possível, faz indispensável a prática de uma ponderação orientada a fins. (ALEXY, Robert. Epílogo a la teoría de los derechos fundamentales. Trad. Carlos Bernal Pulido. Madrid: Fundacion Beneficentia et peritia juris, 2014). Em síntese: os direitos fundamentais são enfraquecidos ao transformarem-se em mandados de otimização e podem desaparecer no turbilhão da ponderação irracional.

16 Segundo Alexy, para Böckenförde, o caráter de princípios acarreta a mudança do papel dos direitos fundamentais em relação à teria clássica (no modelo clássico, os direitos fundamentais alcançavam apenas uma parte do sistema jurídico: a relação entre o Estado e o cidadão). Como princípios, os direitos fundamentais têm efeitos em todo o ordenamento e geram, por isso, uma eficácia expansiva a todos os âmbitos jurídicos. Isso conduz, necessariamente, a uma eficácia horizontal (ou eficácia frente a terceiros) e a um reconhecimento de que existem conteúdos jusfundamentais de proteção, de segurança social e de organização e procedimento que exigem uma atuação positiva do Estado. Assim, os direitos fundamentais se converteriam nos princípios de maior hierarquia dentro do ordenamento jurídico. (Op. Cit., p. 29). O ponto de partida da crítica é a diferença entre: 
Alexy aponta em decorrência das objeções de Habermas e de Böckenförde, existiriam duas alternativas: a) compreender os direitos fundamentais como princípios em um Estado jurisdicional ou b) compreender os direitos fundamentais como clássicos direitos de defesa em um Estado de legislação parlamentar; e questiona se haveria somente essas duas possibilidades. Está a tratar da distinção da Constituição como ordem fundamental (teoria dos princípios) ${ }^{17}$ ou como ordem marco (ideia da otimização). ${ }^{18}$ E pontua que segundo a teoria dos princípios, uma boa Constituição tem

a) direitos fundamentais como clássicos direitos de defesa do cidadão frente ao Estado e b) os direitos fundamentais como normas de princípios. Segundo Böckenförde: O ordenamento jurídico em seu conjunto está - no nível das normas de princípio com tendência de otimização - já contido na Constituição. Somente falta sua concretização." Portanto, seria a Constituição uma espécie de "ovo jurídico originário" . Nesse contexto, a concepção de direitos fundamentais como mandamentos de otimização conduz a uma modelo no qual o legislador perderia toda autonomia uma vez que sua atividade se esgotaria na mera definição daquilo que está decidido pela Constituição e o processo político-democrático perderia consideravelmente seu significado (haveria a mudança do Estado de legislação parlamentar para o Estado jurisdicional). Op. Cit., p. 32).

17 Alexy aponta que uma Constituição é uma ordem fundamental em sentido quantitativo se não confia nada à discricionariedade do legislador (tem previstos para todos os casos mandamentos ou proibições, como na ideia de "ovo jurídico" originário). E no sentido qualitativo, se, mediante os seus mandamentos, se decidem assuntos fundamentais para a comunidade. $\mathrm{O}$ autor ainda pondera que uma Constituição pode decidir assuntos fundamentais e ser uma ordem fundamental, mas, ao mesmo tempo, deixar muitas perguntas em aberto (e ser uma ordem marco). (op. Cit., p. 57).

18 Alexy aponta que o Modelo material-procedimental de ordem marco pressupõe que algumas coisas são confiadas à discricionariedade do legislador e outras não. A metáfora do marco pode ser precisada da seguinte maneira: o marco é aquilo que está ordenado e proibido; o que se confia à discricionariedade do legislador é aquilo que não está ordenado e nem proibido. Essa margem de ação é do tipo estrutural, ou seja, os limites de ação do legislador estão naquilo que a Constituição permite ou não proíbe definitivamente. (op. Cit., p. 54). 
que combinar esses dois aspectos: dever ser tanto uma ordem fundamental como uma ordem marco. ${ }^{19}$

A ideia de otimização não se trata de uma otimização até o ponto máximo, mas se trata da proibição de sacrifícios desnecessários aos direitos fundamentais. Portanto, o subprincípio da necessidade leva à escolha dos melhores meios. Neste ponto se encontra os valores da adequação e necessidade. São duas máximas cobertas simultaneamente pelo devido processo legal em sentido substantivo ou pela máxima da razoabilidade. A partir disso, o papel da jurisdição constitucional é um papel de controle do excesso. A teoria constitucional comprometida com uma reserva de justiça dos direitos fundamentais necessariamente ensejará uma interpretação constitucional substantiva e não desintegradora do conteúdo dos direitos fundamentais.

Mas também terá que admitir que são muitos os autores do texto constitucional, e que a Constituição é compromissória com seu tempo. Em verdade é preciso uma consciência de que há conflito subjacente e de que a Constituição não é transparente. Não é possível uma hiperinterpretação constitucional ou uma desintegração de seu conteúdo. E nesse sentido o resgate de uma teoria de justiça e de uma reserva de justiça em face dos direitos fundamentais. ${ }^{20}$

19 "Isso é possível se, em primeiro lugar, a Constituição ordena e proíbe algumas coisas, quer dizer, estabelece um marco; se, em segundo lugar, confia outras coisas à discricionariedade dos poderes públicos, ou seja, deixa abertas margens de ação; e, em terceiro lugar, se mediante seus mandamentos e proibições decide aquelas questões fundamentais para a sociedade que podem e devem ser decididas por uma Constituição." (op. Cit. P. 60)

20 Nesse sentido cabe a doutrina de Eros Roberto Grau, para quem o sentido da Constituição já se encontra em seu texto, só precisa ser encontrado, construído, numa estrutura onde o limite entre o que é dado e o que é construído é realizado solidariamente. É uma obra coletiva ao alcance de todos, mas não é total. A origem é origem e não será mudada. Seu significado relacionado à reserva de justiça dos direitos fundamentais se 
O Direito Constitucional no Brasil deve ser fático mas sobretudo contra fático. A proposta é dissecar a tensão entre normatividade e realidade constitucional, de modo a construir uma teoria constitucional adequada ao contexto. Clémerson Merlin Clève nesse ponto afirma que se o Direito não é fático não se sustenta e se não é contra fático não avança e essa questão é levada ao Direito Constitucional, não se podendo descontextualizar. E nesse sentido o papel da jurisdição constitucional deve ser visualizado, especialmente para a concretude dos direitos fundamentais estabelecidos na Constituição. ${ }^{21}$

A jurisdição constitucional é instrumento para proteção de direitos fundamentais. Isso porque o rol de direitos fundamentais inscrito na Constituição expressa valores compartilhados pela comunidade política e nesse sentido é que se afirma o papel da Corte Constitucional reposicionado para uma atuação de defesa de reserva de justiça em direitos fundamentais.

A discussão da reserva de justiça dos direitos fundamentais também exige a retomada da questão do custo dos direitos fundamentais. Para Comella, os direitos fundamentais têm custos, mas é uma boa estratégia inseri-los na Constituição a fim de exigir que as instituições os respeitem. Para materializar esse controle, o papel dos juízes é fundamental. Na jurisdição constitucional abstrata, os julgadores podem ter o ambiente necessário à decisão e teriam tendência a levar a sério os valores constitucionais. Por outro lado, exige-se deles coerência e objetividade em suas decisões com base em

mantém. (GRAU, Eros Roberto. Ensaio E Discurso Sobre A Interpretação/ Aplicação Do Direito. 5. ed. São Paulo: Malheiros Editores, 2009. v. 1. P. 227.)

21 CLEVE, Clémerson Merlin. Direitos Fundamentais e Jurisdição Constitucional, RT (Co-coord., 2014). 
razões que transcendam crenças pessoais, pois os critérios de decisão devem ser universalizáveis. ${ }^{22}$

E se retoma igualmente a ideia de que se deve pensar as decisões do Poder Judiciário também como decisões políticas de modo a afastar a desigualdade insuportável e buscar materializar a máxima de Dworkin de que todos devem ser tratados com igual consideração e respeito. Para Dworkin são os direitos individuais trunfos contra a maioria. Mas o que ele traz em relação a integridade, coerência e necessidade de construção de um arsenal decisório sério, de levar em consideração todos os argumentos por conta do fórum de princípios e a ideia de tratamento de todos com igual consideração é muito importante e revolucionária. As teorias da justiça são uma expressão de filosofias morais que mais recentemente mergulharam na filosofia política. Quando Dworkin fala de fórum de princípios está no contexto dessa tradição. ${ }^{23}$

Portanto é preciso dizer que, em muitos casos, em relação a questões que não são circunstanciais, o fórum mais interessante para o debate pode ser o fórum da corte constitucional, ouvidos todos os argumentos.

Isso explica a necessidade dessa dimensão de racionalidade, mas não o problema dos limites. Até onde vai ou se pode ir? Onde uma certa atuação um controle forte é legitimo e onde a própria arquitetura da democracia exige um controle débil? E isso a metódica jurídica não vai dizer,

22 La esperanza, en última instancia, es que la existencia de un "foro de los principios" en el poder judicial, como lo llama Dworkin, eleve la probabilidad de que la comunidad política como un todo adopte decisiones adecuadas en el ámbito de los derechos fundamentales. COMELLA, Víctor Ferreres. Una Defensa del Modelo Europeo de Controle de Constitucionalidad, op. Cit., p.72.

23 DWORKIN, Ronald. O Império do Direito. São Paulo: Martins Fontes, 1999. 
é questão dos poderes e de política que vai responder.

No Brasil, o debate se desloca da questão da legitimidade constitucional para o exercício da jurisdição constitucional. Embora pareça que a jurisdição constitucional está sendo questionada em sua legitimidade, com defesa de uma certa fraqueza. Essa é a discussão subjacente neste ensaio. Jurisdição constitucional forte ou débil. Diálogo constitucional e disputa. E Clève afirma que o diálogo constitucional pode ser cooperativo ou conflitivo. ${ }^{24}$

Cass Sunstein nesse sentido defende o compromisso com direitos sociais e aponta a ideia de que o direito constitucional contemporâneo não é imparcial, e se encontra a favor do status quo e por isso mesmo tende a tratar qualquer iniciativa que o distancie do presente estado de coisas como uma "tomada de posição" ou uma ação parcial. Defende que, quando o status quo não é justo e nem trata a todos por igual, é esse mesmo respeito à imparcialidade que exige a introdução de reformas e um renovado ativismo estatal. Critica o estado de coisas dominante, não questionado e constitucionalmente legitimado. ${ }^{25}$

Sunstein ainda afirma que todos os direitos, e não apenas os sociais, custam dinheiro, e a ideia de que não existem situações de não intervenção estatal, apenas melhores ou piores intervenções, além das ideias de que Mercado e riqueza dependem da ação do governo e de que não há uma distinção significativa entre direitos negativos e positivos. ${ }^{26}$

E nesse contexto é evidente a necessidade de discussão das capacidades institucionais da organização constitucional brasileira e do processo decisório da jurisdição constitucional

24 CLEVE, Clémerson Merlin, op. Cit.

25 SUNSTEIN, Cass, op. Cit.

26 SUNSTEIN, Cass. Free Markets and Social Justice, 2002 e The Cost of Rights, 1999. 
brasileira.

\section{Capacidades Institucionais e Processo Deci- sório da Jurisdição Constitucional - Crise de Representação e Necessidade de Construção de Um Novo Espaço-Temporal para o Direito Constitucional}

É preciso conceber uma estrutura constitucional adequada para arranjos de direitos fundamentais, capaz de atuar na perspectiva das liberdades, exigindo-se um arranjo institucional que multiplique as possibilidades de liberdade. Um arranjo institucional que permita uma ação estatal que vá além da perspectiva constitucional de abstenção, com prestações estatais adequadas à reserva de justiça necessária aos direitos fundamentais, mais inclusiva e emancipatória. A discussão do presente é sobre as capacidades das instituições constitucionais responderem adequadamente à demanda por direitos. Não se pode desenvolver sistemas de direito que suponham que são operados sozinhos ou atribuir ao juiz o papel de Hércules nessa exegese.

E essas capacidades institucionais são fortemente afetadas pelo arranjo federativo brasileiro. $\mathrm{O}$ desequilíbrio na distribuição de competências entre as unidades federativas (com prevalência do ponto de vista material e legislativo para a União) e entre os poderes da República (com usurpação de competência pelo Executivo, timidez do Legislativo e ativismo no Judiciário) estabelecido na Constituição de 1988 produz uma significativa afetação da capacidade institucional de se responder às demandas por direitos fundamentais. Se o Estado é uma associação política de seres emancipados faz-se necessário pensar sua estrutura adequada a esse discurso. 
O atual momento do Direito Constitucional brasileiro é o de discussão de uma estrutura que amplie as capacidades institucionais, de modo a permitir a materialização do discurso emancipatório da Constituição. Paraisso faz-se fundamental que, além de se discutir a estrutura dos poderes, se insira ao debate as capacidades do processo decisório do Supremo Tribunal Federal.

E nesse sentido o Direito Constitucional precisa abrir suas fronteiras e permitir o diálogo com a Ciência Política, a Ciência da Administração e com o Direito Administrativo, com a Ciência das Finanças e com o Direito Financeiro. E por qual razão? Pela mesma razão sustentada por Sunstein: todos os direitos tem custo. E porque sua implementação dependerá de políticas públicas capazes de dar voz a esse novo discurso constitucional. Nesse contexto de políticas públicas, a interdisciplinaridade é a base da discussão.

Toda atuação estatal deve estar pautada pela busca da manutenção e respeito ao núcleo de direitos fundamentais do cidadão, constitucionalmente estatuídos. E nesse sentido é que políticas públicas devem ser formuladas e implementadas. E para isso se faz necessário, para usar a expressão de Clève, uma nova maquinaria constitucional, adequada à implementação de direitos fundamentais. ${ }^{27}$

27 O principal mecanismo de ação estatal no sentido de implementar um Direito Fundamental Social são as políticas públicas, cuja formulação na seara judicial se encontra ainda em construção. De todo modo, Maria Paula Dallari Bucci cuida elaborar uma conceituação jurídica da política pública: Política pública é o programa de ação governamental que resulta de um processo ou conjunto de processos juridicamente regulados - processo eleitoral, processo de planejamento, processo de governo, processo orçamentário, processo legislativo, processo administrativo, processo judicial-visando coordenar os meios à disposição do Estado e as atividades privadas, para a realização de objetivos socialmente relevantes e politicamente determinados.(BUCCI, Maria Paula Dallari, Direito Administrativo e Políticas Públicas. São Paulo, Editora Saraiva, 2006, p.39) 
O que se verifica é que as políticas públicas se apresentam como um elo entre o Estado e a sociedade, desempenhando um papel fundamental no Estado Democrático de Direito, haja vista que se mostram como a ferramenta de concretização dos postulados constitucionais. Nessa perspectiva, Thiago Lima Breus aduz que "a estrutura em alusão (...) deverá estar vinculada a uma noção ampla conferida à ideia de política pública". ${ }^{28}$

Por sua vez, Andreas Krell crê a possibilidade de atuação do poder judiciário inclusive na formulação de políticas públicas. $O$ autor sinaliza que onde já se mostrou implementado o serviço público, quando há uma falta dele, a situação pode ser facilmente contornada mediante a impetração de um mandado de segurança. ${ }^{29}$

28 BREUS, Thiago Lima. O governo por contrato(s) e a concretização de políticas públicas horizontais como mecanismo de justiça distributiva. Tese (Doutorado em Direito) Programa de Pós-Graduação em Direito da Universidade Federal do Paraná, 2015. Oswaldo Canela Junior confere às políticas públicas mecanismos de efetivação dos direitos fundamentais, aduzindo que "as políticas públicas, irradiadas através dos núcleos constitucionais, representam a satisfação espontânea dos direitos fundamentais sociais pelo Estado" (CANELA JUNIOR, Oswaldo. Controle Judicial de Políticas Públicas. São Paulo, Editora Saraiva, 2009, capítulo I, seção 9). Em conformidade com Eduardo Appio, pode-se afirmar que o controle de políticas públicas pelo poder judiciário pode ser realizado em três momentos, preventivo, concomitante e posterior ao ato. Ao que se refere ao primeiro, é dado o nome de controle de formulação de políticas públicas (APPIO, Eduardo. Controle judicial das políticas públicas no Brasil. Curitiba, Juruá, 2006.) De acordo com Luis Roberto Barroso, a Constituição ao proteger os Direitos Fundamentais determina a adoção de políticas públicas de modo a realizá-los, sendo que, uma vez não efetivados cabe ao Poder Judiciário atuar de modo a garantir que um Direito Fundamental seja implementado (BARROSO, Luís Roberto. O novo direito constitucional brasileiro: contribuições para a construção teórica e prática da jurisdição constitucional no Brasil. Belo Horizonte: Fórum, 2012.)

29 KRELL, Andreas. Direitos sociais e controle judicial no Brasil e na Alemanha: os (des)caminhos de um direito constitucional "comparado". Porto Alegre: Fabris, 2002. 
Entretanto, a dificuldade se apresenta aparente nas situações onde o Poder Público se mostra inerte ou omisso. Neste sentido, o autor questiona até que ponto deve ser tolerado a não atuação do Poder Judiciário na verificação de uma 'deterioração' de um serviço social básico, tal como a saúde ou educação. Nesta mesma posição, Ada Pelegrini Grinover estampa que “o Judiciário pode intervir nas políticas públicas entendidas como programas e ações do poder público objetivando atingir os objetivos fundamentais do Estado quer para implementá-las, quer para corrigi-las quando equivocadas". ${ }^{30}$

O limite do controle judicial de políticas públicas se traduz muito significativamente na discussão do ativismo judicial. O questionamento que se faz, atualmente, portanto, resta justamente no limite de referida atuação. A esse propósito cabe trazer as elucidações de Ana Paula de Barcellos, que assinalou que não se pode pretender uma invasão da Política, assim como tampouco se pode permitir que certos fins estabelecidos pela Constituição como prioritários não sejam efetivados. Assim, "não se trata da absorção do político pelo jurídico, mas apenas da limitação do primeiro pelo segundo". Mas talvez essa seja justamente a questão. Sem a dimensão política, o Direito Constitucional não está dando conta dos atuais problemas da realidade social. ${ }^{31}$

A dimensão política deve ser considerada e esse é o discurso das capacidades institucionais e do processo decisório do STF. Não há como analisar-se a jurisdição constitucional do STF sem a exata percepção de dimensão política de suas

30 GRINOVER, Ada Pelegrini. Os poderes do juiz e o controle das decisões judiciais: Estudos em Homenagem à professora Teresa Arruda Alvim Wambier .São Paulo, Revista do Tribunais, 2008, p. 36.

31 BARCELOS, Ana Paula de. Ponderação, Racionalidade e Atividade Jurisdicional. Rio de Janeiro, Editora Renovar, 2005, p.240. 
decisões, e nesse ponto o controle de políticas públicas precisa ser rediscutido inserido no discurso das capacidades institucionais.

A reconfiguração da maquinaria constitucional exige análise de políticas públicas, o que exige gestão, formulação de indicadores, acompanhamento passo a passo do processo de tomada de decisão. O Direito Constitucional precisa de efetividade. A afirmação do discurso constitucional de emancipação acaba por se esvaziar se institucionalmente não se possibilitar a materialização das conquistas em direitos fundamentais.

E nesse ponto oportuna a fala de Jorge Reis Novais sobre direitos fundamentais e justiça constitucional e sobre a preocupação do atual Direito Constitucional não conseguir atender as exigências do novo constitucionalismo. ${ }^{32} \mathrm{O}$ problema é de efetividade. E de qual será o discurso da jurisdição constitucional: débil ou forte. Nessa discussão também está, além do papel da jurisdição, qual o grau de deliberação e disputabilidade intersubjetiva. $\mathrm{O}$ atual arranjo institucional permite poucos espaços de verdadeira disputabilidade e deliberação e por óbvio que essa realidade afeta o processo decisório do STF e traz consequências para a reserva de justiça em face dos direitos fundamentais. ${ }^{33}$

Há um déficit de legitimidade e de fundamentação decisória que afeta as capacidades institucionais de dar efetividade aos direitos fundamentais. Por isso a necessidade de um novo arranjo institucional, que atenda ao pluralismo de atores sociais e políticos. Nesse novo arranjo é necessária

32 NOVAIS, Jorge Reis. Direitos fundamentais e justiça constitucional em Estado de Direito Democrático. Coimbra: Coimbra Editora, 2012, pp. 137257.

33 Essa realidade pode bem ser evidenciada atualmente no Plenário virtual do STF, onde os ministros votam em tempos distintos, sem deliberação ou disputabilidade e nesse ponto se coloca a crise de legitimidade. 
a construção de um novo espaço-temporal para o direito constitucional, numa a proposta de reestruturação a partir da arena política e da ampliação democrática do rol de atores sociais e políticos. Diálogo institucional está no cerne da questão.Capacidade de diálogo entre os Poderes para conferir efetividade aos direitos fundamentais é determinante para a sustentação democrática da proposta de igualdade de respeito e consideração a todos proposta por Dworkin.

$\mathrm{O}$ arranjo institucional deve permitir uma racionalidade adequada à discussão dos casos difíceis em matéria de direitos fundamentais e a resposta correta, na fala de Dworkin, muitas vezes não é possível de ser pensada a priori e precisa de um diálogo institucional entre os Poderes mais maduro. Nesse ponto novamente o discurso constitucional terá que se definir, optando por um constitucionalismo forte ou por um constitucionalismo débil. $\mathrm{O}$ modelo de uma sociedade aberta parte da premissa de que um modelo teórico de decisão judicial vai resolver o problema da jurisdição constitucional. O ideal é que se parta de um horizonte aberto de interpretação e o novo constitucionalismo prevê a lei nos termos dos direitos fundamentais e não o contrário.

A crise de representação não pode ser pontuada sem a análise da doutrina de Jeremy Waldron, que se dirige a afastar o fundamento de legitimidade da existência institucional da jurisdição constitucional e da própria constitucionalização dos direitos, com base na garantia dos direitos fundamentais. Em sua essência, Waldron questionou o desacordo existente nas sociedades sobre o conteúdo e o alcance dos direitos fundamentais, pelo que a solução se daria a partir de uma teoria da autoridade, que definisse quem deveria deter poder para declarar o conteúdo dos direitos.

Esse questionamento decorre da percepção de que a justiça constitucional perderia a sua legitimação quando 
implicasse na substituição de um procedimento democrático de decisão, em que cada cidadão tomaria parte do processo, para algum antidemocrático, em que uma minoria elitista tomaria a si esta função. ${ }^{34}$

Diante da crise de representação, Jorge Reis Novais analisa a situação a partir da perspectiva dos direitos fundamentais como trunfos contra a maioria. A questão fundamental da relação entre direitos fundamentais e a democracia do ponto de vista jurídico-constitucional não residiria na definição do conteúdo dos direitos, mas em se saber se houve violação desses direitos pelo poder público o que, em Estado de Direito, implicaria em concluir se a violação foi excessiva, desarrazoada, desproporcional ou afrontou a igualdade e a segurança jurídica; de forma que isto alcançaria, desde já o preceito da dignidade da pessoa humana. A tarefa para a solução da medida restaria melhor delegada ao encargo do Poder Judiciário, que seria o mais apto para tal, seja de decidir sobre possível violação a princípios político-

34 WALDRON, Jeremy. A dignidade da legislação. Tradução de Luís Carlos Borges. São Paulo: Martins Fontes. 2003. Waldron analisa a a conveniência do controle judicial de constitucionalidade, opondo-se radicalmente à Dworkin, sustentando a total ilegitimidade da revisão judicial, numa abordagem profunda que não se resume a uma mera contra-argumentação da leitura moral. A preocupação é resgatar a dignidade da legislação, buscando as razões para a sua indignidade objetivando colocar a lei no centro dos estudos da filosofia política. Parte da premissa que o direito e os desacordos caminham lado a lado e a existência de desacordos não significaria uma crise no direito, pois estes são da sua própria essência. Waldron coloca o direito à participação nas decisões públicas como o "direito dos direitos", cabendo à lei decidir por último nos casos de discordância moral entre os membros da sociedade e confronta a ideia de que os Tribunais são as instâncias mais adequadas para resolver questões de desacordo moral, já que o debate legislativo tende a ser viciado. (WALDRON, Jeremy. O judicial review e as condições da democracia. Tradução de Julia Sichieri Moura. In.: Limites do controle de constitucionalidade. Coleção ANPR de direito e democracia. Antônio Carlos Alpino Bigonha e Luiz Moreira (Orgs.). Rio de Janeiro: Lumen Juris, 2009. p, 243-270). 
-constitucionais do que o próprio poder político, que estaria passível de ter sido arguido sobre eventual desrespeito. ${ }^{35} \mathrm{~A}$ discussão sobre a última palavra, nesse ponto, permeia o debate constitucional norte americano.

A sociedade precisa enfrentar esse debate e o novo constitucionalismo reconhece a importância da moral na questão da legitimidade das instituições e na validade do direito, na medida em que direito insuportavelmente injusto não é direito. Há conexão entre direito e moral, há uma ligação substantiva com a moral que precisa ser considerada.

E neste ponto cabe a pergunta: o Estado democrático de Direito exige racionalidade? Clève afirma que sim. ${ }^{36}$ Para o autor, conflito e consenso estão presentes nesse diálogo institucional e o maior consenso é que o conflito será resolvido com a argumentação. A democracia pressupõe instituições que não apenas proíbam os excessos, mas que promovam o acesso aos direitos fundamentais. E somente se faz isso com instituições. Daí a necessidade de um novo arranjo institucional.

\section{Conclusões: Por um Direito Constitucional Efetivo, Inclusivo, Dialético, Reflexivo, Dia- lógico, de Disputabilidade e Aberto.}

A exigência de um novo arranjo institucional passa pela discussão da legitimidade democrática do controle judicial de constitucionalidade e a interação entre o STF e o legislador. Nesse sentido Conrado Hubner Mendes aponta para uma teoria política de ação do STF. Defende que o discurso

35 NOVAIS, Jorge Reis, op. Cit., p. 234.

36 Cleve, Clemerson Merlin. Governo Democrático e Jurisdição Constitucional. Porto Alegre, Editora Fórum, 2016. 
da última palavra é míope e incompleto, um apelo teórico que não se sustenta nem empírica nem teoricamente. ${ }^{37} \mathrm{O}$ autor também postula que numa cultura política preocupada em discutir justificativas por trás de decisões coletivas, que a condição de legitimidade é que todas as instituições interajam por maio da razão pública e a isso denomina de demanda argumentativa. ${ }^{38}$

Mas é possível enquadrar a atuação do STF como de modelo de revisão judicial? Como contra poder e operador de veto e não como reserva de justiça da democracia? Seria desejável? O atual arranjo institucional permite uma modificação dessa posição? O autor aponta que é indispensável para discutir revisão judicial na democracia a análise da teoria da separação de poderes de quem decide o que, e como e quando e por que decide. Nesse sentido no Brasil o debate substantivo a ser travado implica numa concepção de Corte Constitucional pro ativa e especialmente contra majoritária na defesa de direitos fundamentais, notadamente em face de posições conservadoras do legislativo. ${ }^{39}$

37 MENDES, Conrado Hubner. Direitos Fundamentais, separação de poderes e deliberação. São Paulo: Saraiva, 2011

38 MENDES, Conrado Hubner, idem.

39 Em sentido contrário, afirmando que a revisão judicial raramente é contramajoritária, está Barry Friedman. The politics of judicial review, Texas Law Review 84:257, 2005, p. 267 e p. 269. Conrado Hubner Mendes neste sentido afirma que Friedman se distancia dos outros teóricos sobre teoria do diálogo por rechaçar a dificuldade contramajoritária, compartilhando, neste ponto, elementos da construção coordenada, mas defendendo a soma da opinião pública, ao vislumbrar que o temor da subversão democrática pelo parlamento é tão descalibrado quanto a esperança salvacionista da corte. A corte não tem condições de travar a mobilização majoritária, mas pode contribuir para combater a inércia, a omissão e a indiferença legislativa, reduzir o afastamento e a dissonância entre representante e representado, e reverter o status quo de maneira não revolucionária. Isso é o constitucionalismo democrático. (MENDES, Conrado Hubner. MENDES, Conrado Hubner. Direitos Fundamentais, separação de poderes e deliberação, op. Cit. P. 23. 
Para Mendes a questão de quem e como decide depende muito mais de um desenho institucional do que de uma metódica. Nesse sentido reforço ao argumento de que há necessidade de uma nova teoria política normativa, capaz de fornecer as condições para que os Tribunais Constitucionais efetivamente realizem as promessas do constitucionalismo. E aponta, ainda, que a separação de poderes e seu potencial para a limitação da autoridade política propicia uma base mais sólida para um arranjo institucional de revisão judicial com base na necessidade de proteção dos direitos fundamentais. ${ }^{40}$

Mendes ainda assinala que a Corte Constitucional na revisão judicial atuaria como um contrapeso à política majoritária e como uma instituição capaz de inserir argumento moral na agenda, ao que chama de processo de interlocução institucional. Nesse sentido o STF pode realizar este papel de desaceleração da política majoritária. ${ }^{41}$

E o novo arranjo institucional deve ser pensado a partir de diferentes níveis de interlocução institucional. A dificuldade está na sua operacionalização e no caminho a ser seguido: Trata-se de deliberação interinstitucional (entre parlamentos e cortes) ou intrainstitucional (dentro de parlamentos e cortes)? Em que termos a teoria da última palavra provisória poderia se compatibilizar com rodadas procedimentais? Há possibilidade de compatibilização entre última palavra e diálogo? Estas questões estão em aberto a serem construídas pelo novo constitucionalismo. Mas é certo que o diálogo entre os poderes é indispensável.

A realidade atual impõe ao Direito Constitucional o enfrentamento de diferentes dificuldades institucionais no

40 MENDES, Conrado Hubner. Direitos Fundamentais, separação de poderes e deliberação, op. Cit. P. 27.

41 Idem. 
processo decisório da jurisdição constitucional: a) ausência de motivação suficiente da tomada de decisão; b) ausência de disputabilidade intersubjetiva e de deliberação e debate; c) ausência de argumentação forte; d) ausência de capacidade institucional de colaboração; e) ausência de pauta pré definida e de discussão democrática sobre o que integrará a pauta e d) ausência de uma identidade de corte constitucional no STF.

O estudo de uma nova maquinaria constitucional deve buscar resolver estas questões, de modo a possibilitar diálogo institucional entre os poderes, entre os ramos do direito, acerca das políticas públicas para satisfação dos direitos fundamentais. Há um reconhecimento da necessidade de um acordo institucional diferente. Nesse sentido Gargarella se manifesta defendendo o valor de um sistema constitucional baseado no diálogo democrático, em contraste com sistema um baseado na ideia dos freios e contrapesos.

O objetivo deste modelo é conter e canalizar a guerra política predominante impedindo as mútuas opressões entre os poderes. Afirma que hoje em dia se conta com um sistema constitucional organizado a partir da lógica agonal, da guerra, que não contribui a facilitar um diálogo deliberativo e igualitário, apesar do esforço que alguns fazem neste propósito. ${ }^{42}$ Há necessidade de um momento dialético. ${ }^{43}$

42 “É claro que não se pode dar por óbvios quais são os melhores acordos institucionais. Numerosos autores tem explorado esta questão, no entanto o autor prevê que o funcionamento de um sistema de democracia deliberativa requer uma lógica organizacional e institucional diferente da que oferece os sistemas de freios e contrapesos, toda vez este se orienta a evitar e canalizar a guerra social; enquanto por outro lado, um sistema dialógico requer uma orientação para outros fins, de modo a organizar e facilitar uma conversação estendida entre iguais. "GARGARELLA, Robert. Novo Constitucionalismo Dialógico frente ao Sistema De Freios e Contrapesos. Disponível em http://repositorio.utdt.edu/handle/utdt/10615.

43 Mendes neste ponto oportunamente coloca a posição do STF na retórica do 
E Mendes defende que a radicalização política deve ser substituída por instituições que interajam por meio da razão pública, numa proposta de diálogo institucional, ou de separação de poderes deliberativa. A condição de legitimidade é que todas as instituições interajam por maio da razão pública e a isso denomina de demanda argumentativa. ${ }^{44}$

O novo constitucionalismo, nesse sentido, necessariamente terá que enfrentar a questão dos diálogos constitucionais..$^{45} \mathrm{O}$ constitucionalismo do futuro não é isento de conteúdo e de substância e aqui se retoma a proposta de interpretação substantiva de Sunstein ${ }^{46}$. A ideia da Constituição e do discurso constitucional só tem sentido se prestar-se para a tutela da dignidade da pessoa humana, para a preservação das condições de existência do homem e para a materialização dos direitos fundamentais. E para isso um novo arranjo institucional é necessário.

guardião acanhado: analisa a teoria dos diálogos institucionais à luz do Supremo Tribunal Federal, criticando características do STF como "guardião da constituição" e argumentando que o guardião entrincheirado possui dois vícios relevantes: do ponto de vista normativo, não é compatível com a interação deliberativa e incentiva a dinâmica adversarial e hierárquica, do ponto de vista empírico, produz uma mistificação e atribui à corte um ônus extremamente pesado que ela não é capaz de carregar. MENDES, Conrado Hubner. Direitos Fundamentais, separação de poderes e deliberação, op. Cit. P. 54.

44 Idem.

45 Nesse sentido Rodrigo Brandão debate e critica a ideia de que o Poder Judiciário, notadamente o STF, seria o intérprete único da Constituição e fornece alternativa ao modelo de supremacia judicial ao explorar a potencialidade dos diálogos constitucionais entre os poderes como fórmula mais apta à produção de resultados no campo da hermenêutica. A aplicação desta fórmula possibilitaria correções e controles recíprocos. Como efeito, se minimizaría os riscos de erros e tirania, seja parlamentar, judicial ou de governo.

46 E talvez neste ponto Sunstein estabeleça bases interessantes fundadas na democracia deliberativa: deliberação política, cidadania, acordo como um ideal regulatório e igualdade política. (SUNSTEIN, Cass. Op. Cit.) 
Um direito constitucional efetivo, inclusivo, dialético, reflexivo, dialógico, de disputabilidade e aberto. O Constitucionalismo por vir deverá priorizar essa viragem paradigmática, estará no centro das transformações sociais, garantindo, de forma contra majoritária, uma dogmática constitucional prospectiva e emancipatória, calcada na tutela dos direitos fundamentais, com estruturas abertas ao diálogo, ao debate e à reflexão, que possibilitem respostas aos casos difíceis e efetividade à reserva de justiça dos direitos fundamentais. Que permitam uma construção social livre da desigualdade insuportável.

\section{Referências}

ALEXY, Robert. Epílogo a la teoria de los derechos fundamentales. Madrid: Fundación beneficentia et peritia iuris, 2004.

APPIO, Eduardo. Controle judicial das políticas públicas no Brasil. Curitiba, Juruá, 2006.

Barcelos, Ana Paula de. Ponderação, Racionalidade e Atividade Jurisdicional. Rio de Janeiro, Editora Renovar, 2005.

BARROSO, Luís Roberto. O novo direito constitucional brasileiro: contribuições para a construção teórica e prática da jurisdição constitucional no Brasil. Belo Horizonte: Fórum, 2012.

BRANDÃO, Rodrigo. Supremacía Judicial versus Diálogos Constitucionais: a quem cabe a última palavra sobre o sentido da Constituição? Rio de Janeiro: Lumen Juris, 2012.

BREUS, Thiago Lima. O governo por contrato(s) e a concretização de políticas públicas horizontais como mecanismo de justiça distributiva. Tese (Doutorado em Direito) 
Programa de Pós-Graduação em Direito da Universidade Federal do Paraná, 2015.

BUCCI, Maria Paula Dallari, Direito Administrativo e Políticas Públicas. São Paulo, Editora Saraiva, 2006.

CANELA JUNIOR, Oswaldo. Controle Judicial de Políticas Públicas. São Paulo, Editora Saraiva, 2009.

CLÈVE, Clémerson Merlin. Direitos Fundamentais e Jurisdição Constitucional, RT, Co-coord., 2014.

Governo Democrático e Jurisdição Cons-

titucional. Porto Alegre, Editora Fórum, 2016.

COMELLA, Víctor Ferreres. Una Defensa del Modelo Europeo de Controle de Constitucionalidad. Madrid: Marcial Pons, 2011

DWORKIN, Ronald. O Império do Direito. São Paulo: Martins Fontes, 1999.

GARGARELLA, Robert. Novo Constitucionalismo Dialógico frente ao Sistema De Freios e Contrapesos. Disponível em http:/ / repositorio.utdt.edu/handle/utdt/10615.

GODOY, Arnaldo Sampaio de Moraes. Publicação no consultor jurídico, link: http:/ / www.conjur.com.br/2013-abr-07/embargos-culturais-holmes-sunstein-demonstram-custo-financeiro-direitos\#author.

GRINOVER, Ada Pelegrini. Os poderes do juiz e o controle das decisões judiciais: Estudos em Homenagem à professora Teresa Arruda Alvim Wambier .São Paulo, Revista do Tribunais, 2008.

GRAU, Eros Roberto. Ensaio E Discurso Sobre A Interpretação/Aplicação Do Direito. 5. ed. São Paulo: Malheiros Editores, 2009. v. 1. 
FRIEDMAN, Barry. The politics of judicial review, Texas Law Review 84:257, 2005.

KRELL, Andreas. Direitos sociais e controle judicial no Brasil e na Alemanha: os (des)caminhos de um direito constitucional "comparado". Porto Alegre: Fabris, 2002.

MENDES, Conrado Hubner. Direitos Fundamentais, separação de poderes e deliberação. São Paulo: Saraiva, 2011.

MUELLER, Friedrich. Metódica Jurídica e Sistema Politico. Joinville: Bildung Editora, 2014.

NOVAIS, Jorge Reis. Direitos fundamentais e justiça constitucional em Estado de Direito Democrático. Coimbra: Coimbra Editora, 2012.

SARMENTO, Daniel. "O STF não é o Centro do Constitucionalismo", Entrevista ao Site "Os Constitucionalistas", disponível em http:/ /www.osconstitucionalistas.com. br/o-stf-nao-e-o-centro-do-constitucionalismo.

SUNSTEIN, Cass. A Constituição Parcial. Belo Horizonte: Del Rey Editora, 2008

Free Markets and Social Justice, 2002 e The Cost of Rights, 1999.

WALDRON, Jeremy. A dignidade da legislação. Tradução de Luís Carlos Borges. São Paulo: Martins Fontes. 2003.

. O judicial review e as condições da democracia. Tradução de Julia Sichieri Moura. In.: Limites do controle de constitucionalidade. Coleção ANPR de direito e democracia. Antônio Carlos Alpino Bigonha e Luiz Moreira (Orgs.). Rio de Janeiro: Lumen Juris, 2009. 
Recebido em 06/11/2018

Aprovado em 26/04/2020

Vivian Cristina Lima López Valle

E-mail:vivian.lima@pucpr.br

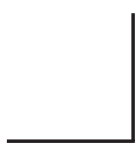


